\title{
Geoconda: A Web Environment for Multi-Centre Research
}

\author{
Christian Setzkorn, Azzam F. Taktak, Bertil Damato
}

Royal Liverpool University Hospital, UK

\section{Introduction}

The collection of data for the validation and generation of hypotheses is a fundamental scientific endeavour. To achieve a low margin of error it is necessary to obtain sufficient numbers of samples. However, this is often difficult, especially if the process being observed is very rare and/or if the collection of data is expensive. This is, for examples, the case for uveal melanomas, which has an occurrence rate of six per million per year [?]. Intraocular melanomas arise from melanocytes in the uvea, which consists of the choroid, ciliary body, and iris. The choroid is a cup-shaped layer of tissue lying between the sclera and the retina, which it nourishes. The ciliary body is a ring-shaped muscular tissue located at the rim of the choroid and encircling the lens, which it stretches to adjust the focal length of the eye. The ciliary body is lined by a secretory epithelium that pumps water into the eyeball, so that its spherical shape is maintained. The iris is a muscular sphincter, which adjusts to the size of the pupil thereby controlling the amount of light entering the eye and improving visual acuity. Patients with uveal melanoma usually have symptoms, such as blurred vision, flashing lights, and visual field loss. Without treatment, many eyes become blind, painful and cosmetically unsightly. For many years, the standard form of treatment was enucleation (i.e. removal of the eye). This has been superseded by a variety of methods aimed at conserving the eye with as much vision as possible. These consist of various types of radiotherapy, laser treatment and local resection. The chances of preserving vision and the eye are related to factors such as tumour size and location as well as secondary effects of the tumour on the eye and unrelated concomitant ocular disease. Approximately $50 \%$ of all patients with uveal melanoma ultimately die of this disease, nearly always as a result of haematogenous spread of tumour (i.e. through the blood circulation) to the liver. The probability of metastatic disease is related to tumour size and extent at the time of treatment, various microscopic features such as cell type, and on cytogenetic abnormalities, particularly those affecting chromosomes 3 and 8 . Metastatic disease rarely responds to treatment and is usually fatal in a few months. The need for multicentre research into uveal melanoma has motivated the Geoconda system described in this chapter. However, the principles described here could also be applied in other research areas. Geoconda is an abbreviation for General Ocular Oncology Database. It uses several web pages and a database to facilitate international collaborations via the Internet and helps, apart from other things, to accumulate sufficient numbers of samples from several different centres around the world. Such collaborations require the standardisation of variables. This is achieved using an interactive multi-stage process that is described in section 2 . This interactive multistage process is also used for other tasks within the Geoconda system. For example, it used for the standardisation of terminologies. Standardisation is of great importance for the success of international collaborations where people from different backgrounds work together. Other objectives of Geoconda are to:

- Develop and maintain rules for collaboration

- Understand essential jargon from different research areas

- Become acquainted with collaborators

- Host discussions

- Collaborate in the preparation of protocols, consent forms and other documents

This chapter is organised as follows. Section 2 briefly describes the technologies that where used to implement the Geoconda system. Section 3 provides an exhaustive description of the Geoconda system. This section is followed by the discussions and the chapter concluded in section 6, which provide avenues for future research. 


\section{Material And Methods}

The Geoconda system utilises several web pages and a relational database. The websites, which are described in more detail in section 3. The system has been implemented using the ASP.NET technology version 1.1, the C-sharp programming language and Visual Studio .NET 2003. These technologies are properties of the company Microsoft. ASP.NET is an abbreviation for Active Server Pages .NET. The interested reader is referred to [1] for more details about the ASP.NET technology. The relational database was implemented using the database system MySQL version 4.0.20a-nt.

To gain more freedom in developing the Geoconda system it was decided to host the website and the database using a professional Internet service provider ${ }^{1}$ rather than the computing service provided by the British National Health Service. The latter has many restrictive measures, which are necessary but hinder the development of systems like Geoconda.

As mentioned in section 1, the collection of data requires the standardisation of variables, which is necessary because different centres might, for example, take measurements using different scales. It is therefore important to achieve an agreement about the variables to be measured, before the data are collected. This is achieved using the afore-mentioned interactive multi-stage process, which is also used to come to an agreement about other items such as glossary items, which are used to standardise terminologies. The Geoconda system allows members to propose different items. Currently, there are seven items, which are listed as follows:

- FAQs

- Positions

- Variables

- Glossaries

- Projects

- Links

- Online Papers

The interactive multi-stage process works as follows. After an item has been proposed (using a particular web form) it has the status 'open' and is stored in the database. The item is then visible to other members of Geoconda who can add comments to it. If a comment is added, an email is sent to the member who proposed the item. The member can then edit the item, allowing him/her to refine it by incorporating comments added by other members. A committee of experts' reviews open items on a regular basis. The chairman of Geoconda invites the experts who are requested to add reviews to items. After the reviewing process, the chairman decides whether the status of the item is changed from 'open' to 'accepted' or 'rejected'. This implements a somewhat democratic system to reach agreements within an international multi-user environment such as Geoconda. Section 3.1 provides more details about the afore-mentioned items.

\footnotetext{
${ }^{1}$ The website of the Internet service provider can be accessed at http://www.titanhosts.net.
} 


\section{Description of the Geoconda Website}

The main web page of the Geoconda system can be accessed at www.geoconda.com. A screen shot of this page is shown in Figure 1. The entry page summarises aims and key principles of the Geoconda system and acknowledges sources of funding. It has to be noted, that only a restricted number of web pages and functionalities can be accessed from the main page because without login. These pages include the: FAQs page, Glossaries page, Links page and the discussion forum.

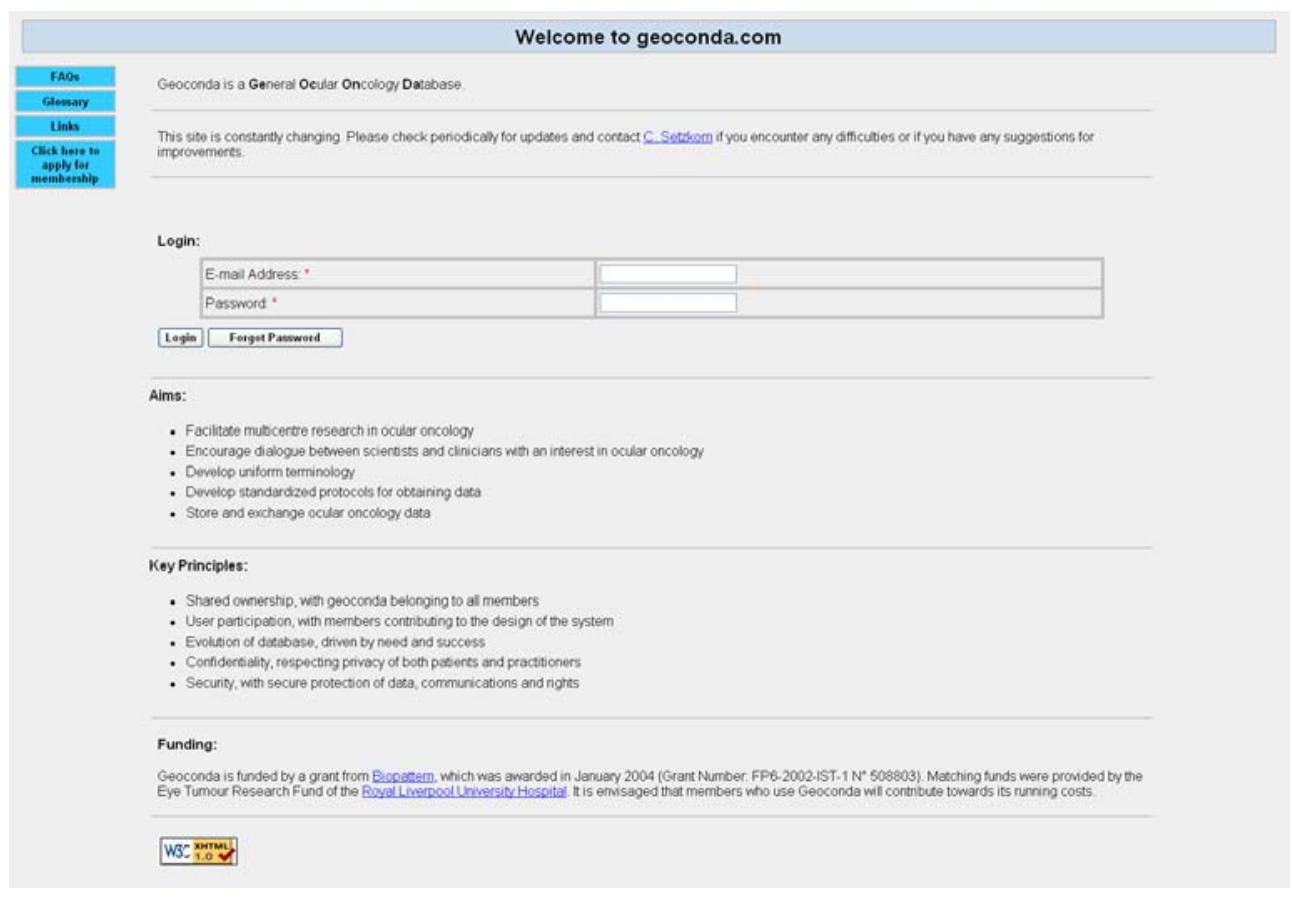

Fig. 1. The main/entry page.

The Geoconda system contains many more pages. Their content is dynamic as the members can change it. To access these pages, accepted members have to login using their email address and a password. Member who forget their passwords can request a randomly generated password by clicking on the button 'Forgot Password'. The password is sent to the provided email address, which is double-checked against the database. Members can then change their password after accessing their personal details. 
People interested in becoming members of Geoconda can apply for membership. Potential members are usually invited by already existing members, for example, at international conferences. However, people interested in contributing to uveal melanoma research are also encouraged to join. Clicking on the button: 'Click here to apply for membership' starts the application process. A form has to be completed, which contains the details summarised in table 1 . The details are temporarily stored in a database and reviewed by a committee of existing members who decide whether or not the member is accepted. Only applicants who have the potential to contribute to the Geoconda system are likely to be accepted.

\begin{tabular}{|c|c|}
\hline Field & Description \\
\hline First name & First name of the applicant. \\
\hline Surname & Surname of the applicant. \\
\hline Email & Email address of the applicant. \\
\hline Password & $\begin{array}{l}\text { Password chosen by the applicant. It has to be noted that the password is en- } \\
\text { crypted before it is stored in the database. This ensures further security. }\end{array}$ \\
\hline Retype Password & $\begin{array}{l}\text { Repeated password. The password has to be exactly the same as the one pro- } \\
\text { vided above. }\end{array}$ \\
\hline Image & This field allows the user to upload a picture of himself/herself. \\
\hline Title(s) & Titles of the applicant (e.g. Prof., Dr. etc.). \\
\hline Qualifications & A list of recent qualifications of the applicant. \\
\hline Positions & This field contains professional positions of the applicant. \\
\hline Contributions & A list of potential contributions of the applicant to the Geoconda project. \\
\hline Date of Birth & Birth date of the applicant. \\
\hline Gender & Gender of the applicant. \\
\hline Address Line 1 & First line of the address. \\
\hline Address Line 2 & Second line of the address. \\
\hline Address Line 3 & Third line of the address. \\
\hline Street & Street of the address. \\
\hline City & City of the address. \\
\hline Country & $\begin{array}{l}\text { Country of residence of the applicant. The country has to be selected from a } \\
\text { dropdown list. }\end{array}$ \\
\hline Postcode & Postcode of the address. \\
\hline Phone Number & Phone number of the applicant. \\
\hline Fax Number & Fax number of the applicant. \\
\hline $\begin{array}{l}\text { Further Details (Re- } \\
\text { search Interests etc.) }\end{array}$ & $\begin{array}{l}\text { This field allows the member to provide further information about him- } \\
\text { self/herself. }\end{array}$ \\
\hline Proposer First Name & First name of the person who encouraged the applicant to apply for membership. \\
\hline Proposer Surname & Surname of the person who encouraged the applicant to apply for membership. \\
\hline
\end{tabular}

Table 1. Details of the membership application form. 
Figure 2 shows the Geoconda main page, which can only be accessed by accepted members. Several other sections/pages can be reached from here by clicking on one of the buttons shown in the navigation panel on the left-hand side.

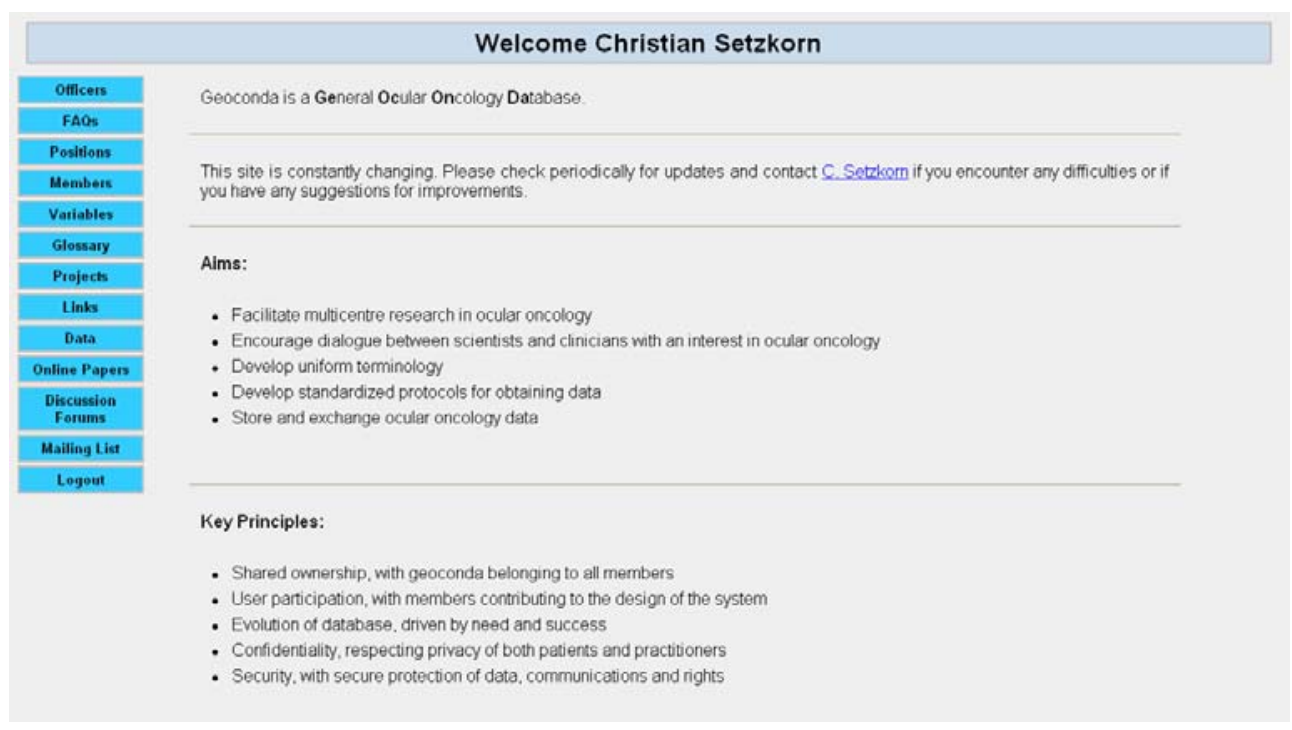

Fig. 2. The main page of the Geoconda website.

There are currently thirteen sections, which are listed as follows:

- Officers

- FAQs

- Positions

- Members

- Variables

- Glossary

- Projects

- Links

- Data

- Online Papers

- Discussion Forum

- Mailing List

- Logout

The 'officers' section contains a list of accepted members who were assigned to a particular position. The reader is referred to section 3.1 for further details about these positions. A part of the officers section is depicted in figure 3. 


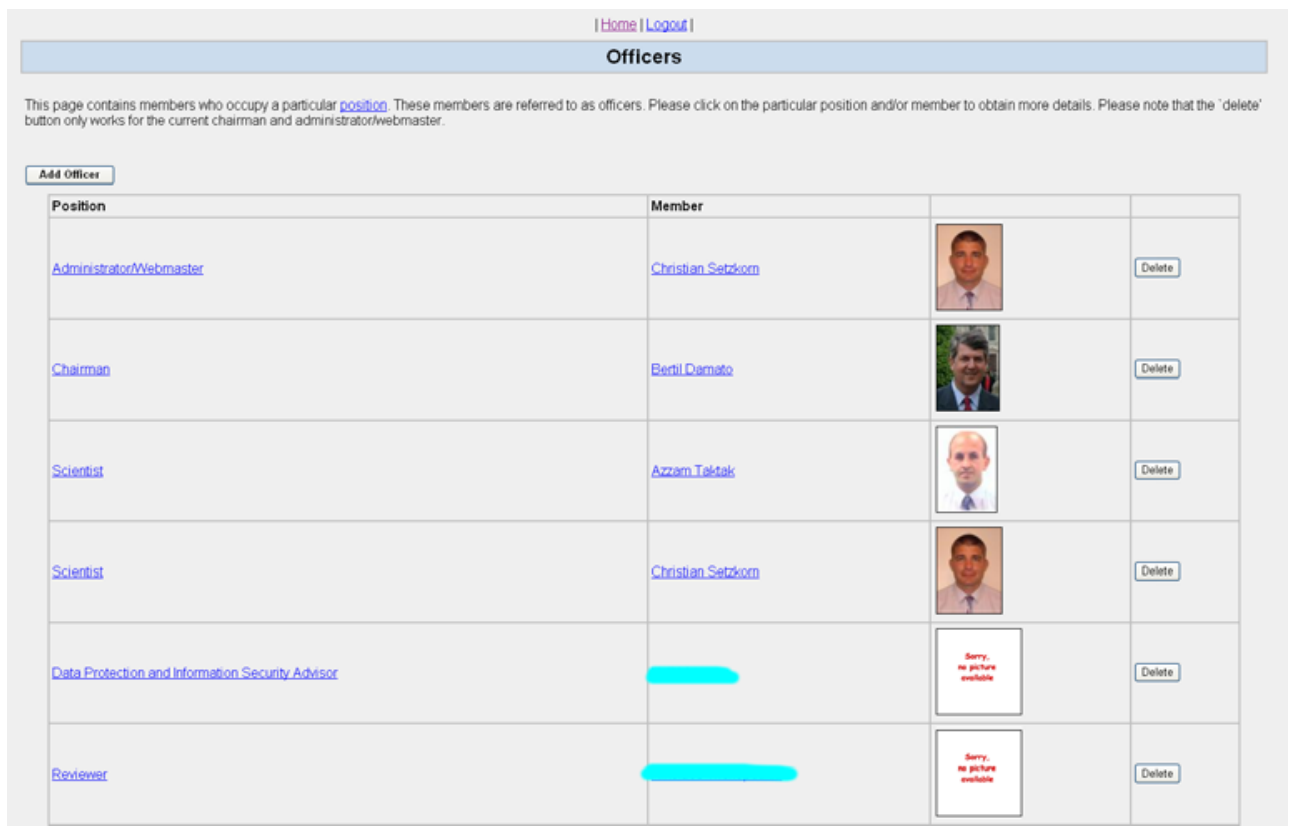

Fig. 3. List of current officers. The names of Geoconda members who are not authors of this chapter are hidden for privacy reasons.

Further details about an officer and the corresponding position can be obtained by clicking on the name or the position respectively. The member section can be reached by clicking on the button 'Members'. Additional details about a particular member can be obtained by clicking on his/her name. Members can change their details by clicking on their name and then on the button 'Edit'. It has to be noted that the 'Edit' button is only visible for the member himself/herself because the Geoconda system knows the identity of the member who has logged in. The details of a particular member are shown in figure 4.

When a member clicks on the button 'Edit', his/her details can be edited as shown in Figure 5. Changes can be stored by clicking on the button 'Update'. The changes are not stored if the member clicks on the button 'Cancel'.

As mentioned earlier, Geoconda allows members to propose different items. Currently, there are seven items, which are listed as follows:

- FAQs

- Positions

- Variables

- Glossaries

- Projects

- Links

- Online Papers

These items are described in more detail in the next section. 


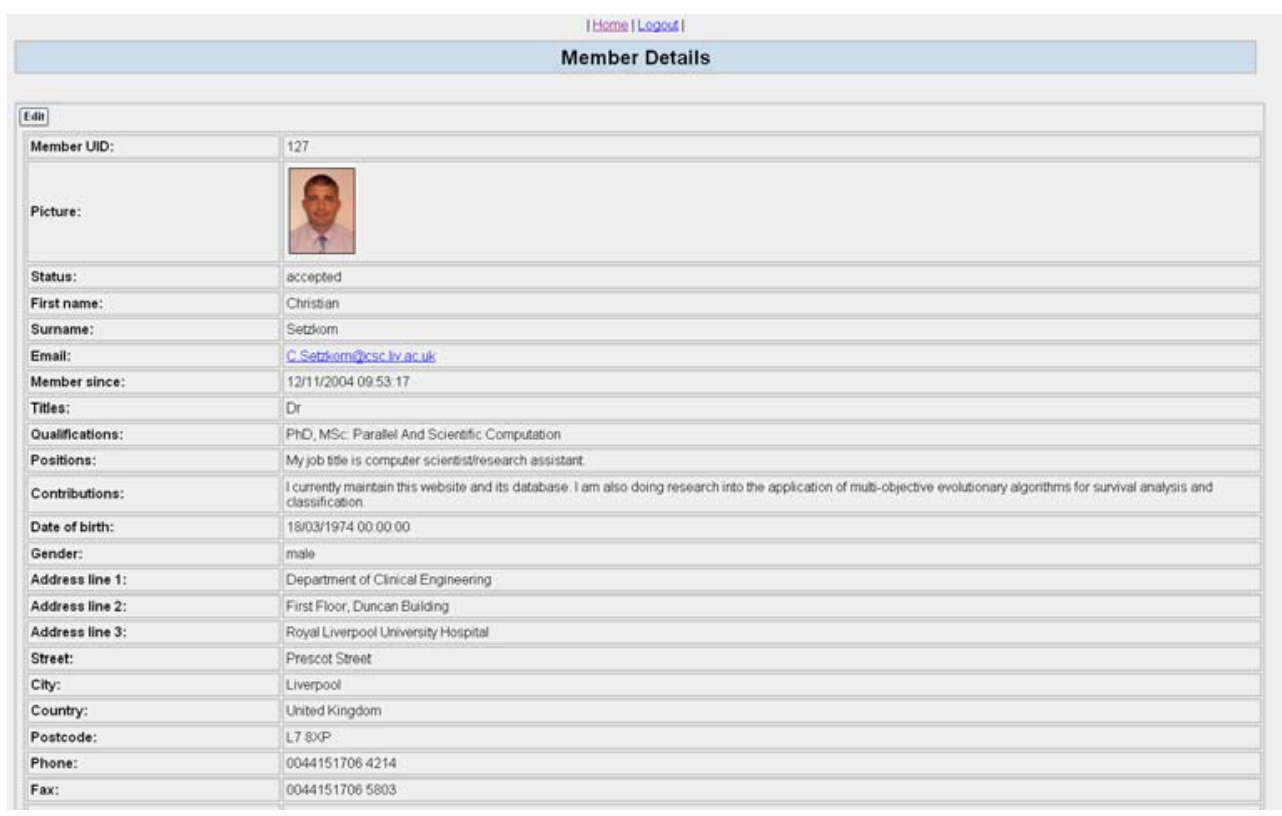

Fig. 4. Details of a particular member.

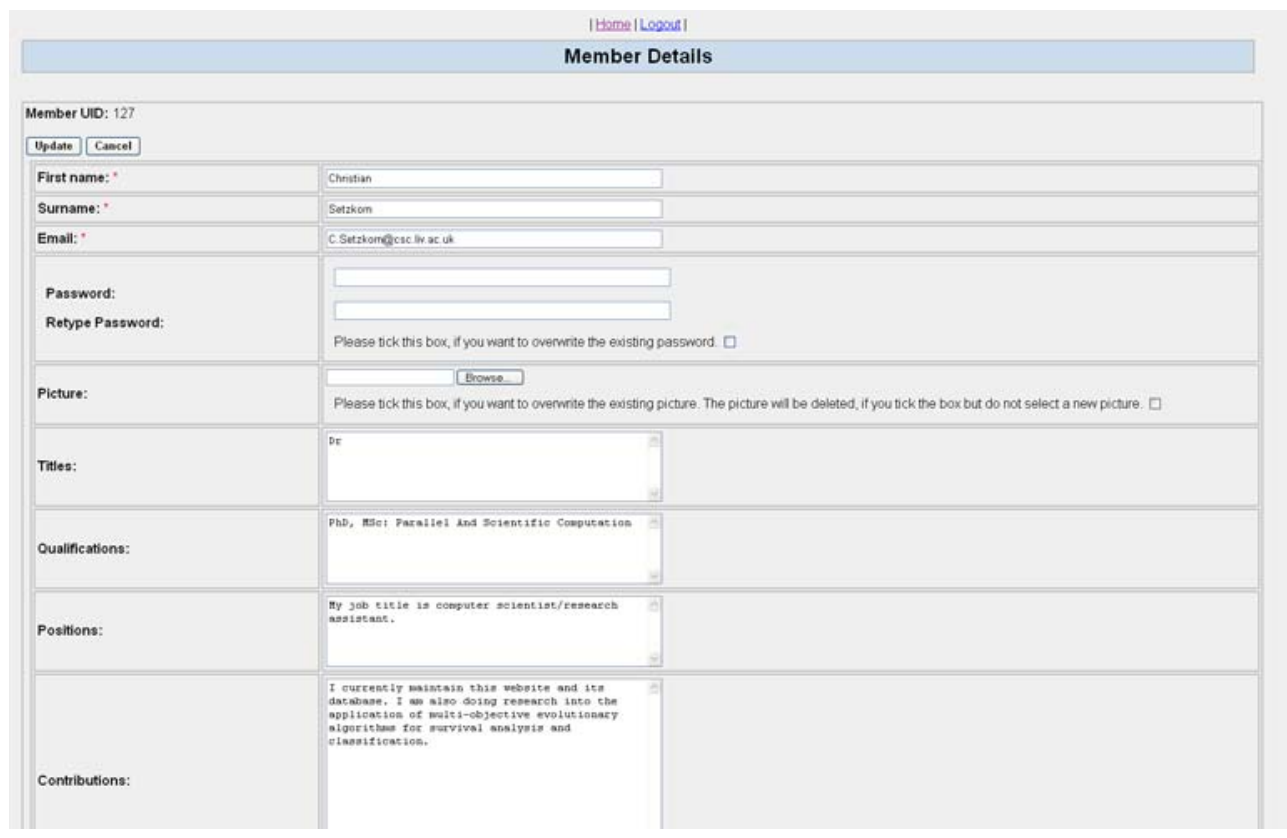

Fig. 5. Member details in the edit mode.

\subsection{Items}

FAQs is an abbreviation for Frequently Asked Questions. One intention of the FAQs is to help new members to understand the Geoconda system. FAQs can also contain the underlying rules of the Geoconda community. As FAQ items can be created/commented by all members, the 
creation of these rules is therefore democratic (see section 2). FAQ items contain the information summarised in table 2 .

\begin{tabular}{|l|l|}
\hline Field & Description \\
\hline Question & Question of the FAQ item. \\
\hline Answer & Answer to the question of the FAQ item. \\
\hline Heading & $\begin{array}{l}\text { FAQs can be categorised using headings that correspond to categories. An al- } \\
\text { ready existing heading can be chosen from a dropdown list. Members can mod- } \\
\text { ify this dropdown list and add new headings. }\end{array}$ \\
\hline
\end{tabular}

Table 2. The fields of a FAQ item.

Figure 6 depicts the FAQ proposal form. The member has to provide the information in the mandatory fields. The item is added to the database (and consequential the website) after pressing the submit button.

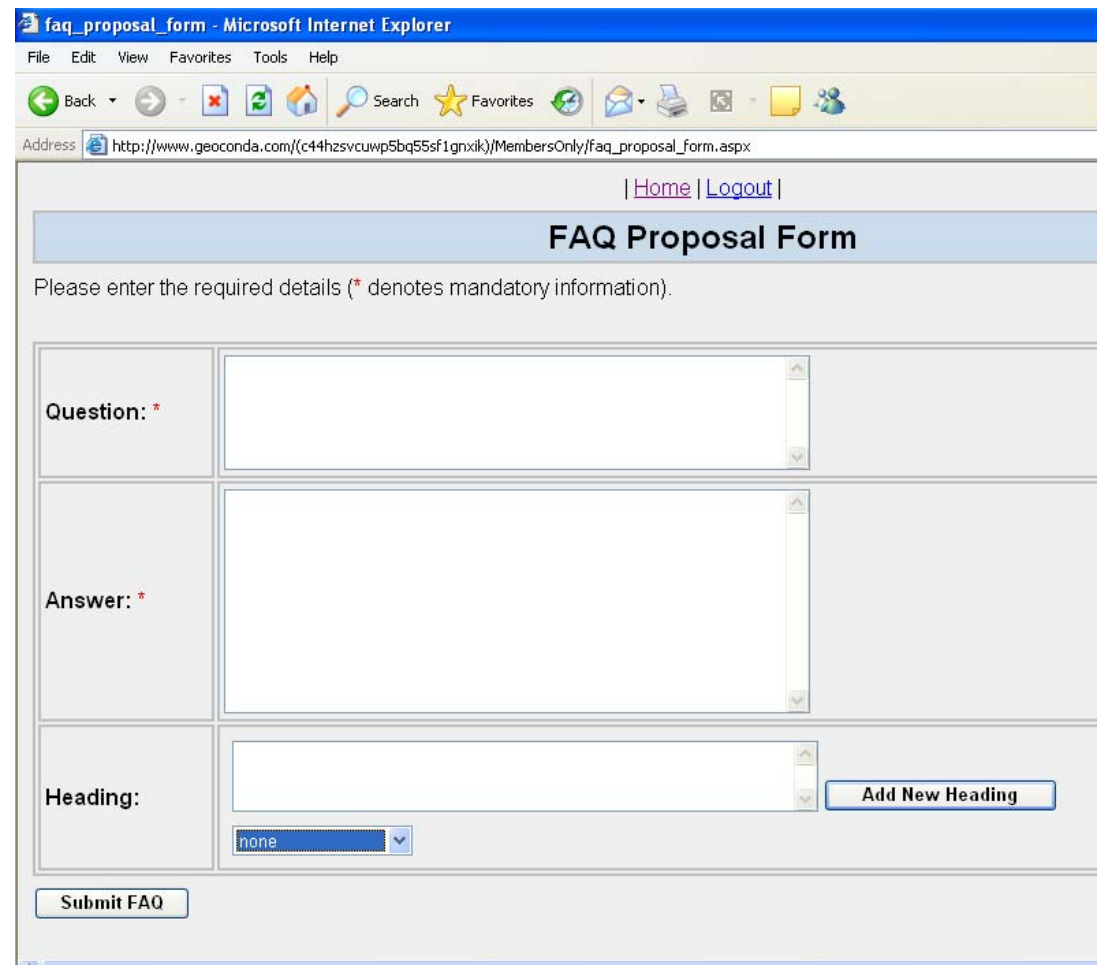

Fig. 6. The FAQ item proposal form. 
Members can assign a FAQ item to one of the headings in the dropdown list. The headings help to categorise FAQ items. New headings can be added to the dropdown list by completing the field 'Heading' and pressing the button 'Add New Heading'. It has to be noted that a new heading is only added if it does not already exist in the database/dropdown list.

FAQ items that currently exist for the heading/category 'Links' are shown in figure 7. The member can press the button 'More Details' to obtain further information about a particular FAQ item. Members can also obtain more details about the member who proposed an item by clicking on his/her name.

\begin{tabular}{|c|c|c|c|c|}
\hline \multicolumn{5}{|c|}{$\begin{array}{l}\text { Sags - Microsoft Internet Explorer } \\
\text { File Edit View Favorites Tools Help }\end{array}$} \\
\hline \multicolumn{5}{|c|}{ 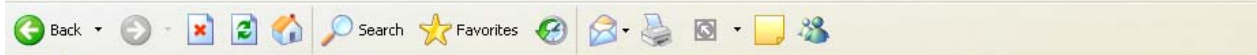 } \\
\hline \multicolumn{5}{|c|}{ Address he http://wwww.geoconda.com/(c44hzsvcuwp5bq55sf1gnxik)/MembersOnly/faqs.aspx } \\
\hline \multicolumn{5}{|c|}{ | Home | Logout | } \\
\hline \multicolumn{5}{|c|}{ FAQs } \\
\hline \multicolumn{5}{|l|}{ Propose FAQ } \\
\hline Heading: Links & & & & \\
\hline Question & Answer & $\begin{array}{l}\text { Proposed } \\
\text { by }\end{array}$ & Status & \\
\hline What are 'Links'? & $\begin{array}{l}\text { Links connect geoconda.com to other websites } \\
\text { that are likely to be of interest to members. }\end{array}$ & $\begin{array}{l}\text { Bertil } \\
\text { Damato }\end{array}$ & open & More Details \\
\hline How are links selected? & $\begin{array}{l}\text { Links are proposed by members in the same way } \\
\text { as other items are put forward. All proposed links } \\
\text { will be checked by geoconda.com reviewers } \\
\text { before being accepted or rejected. }\end{array}$ & $\frac{\text { Bertil }}{\text { Damato }}$ & open & More Details \\
\hline
\end{tabular}

Fig. 7. FAQs for the heading/category 'Links'.

Figure 8 shows the details of a particular FAQ item. It has to be noted that the button 'Edit' is only visible for members who proposed the item and as long as its status is 'open'. Members are encouraged to add comments to items by completing the textbox 'Comment' and pressing the button 'Add Comment'. This principle is followed for all other items within the Geoconda system. It helps members who proposed items to refine them and to make them more likely to be accepted by the committee of reviewers (see section 2). 


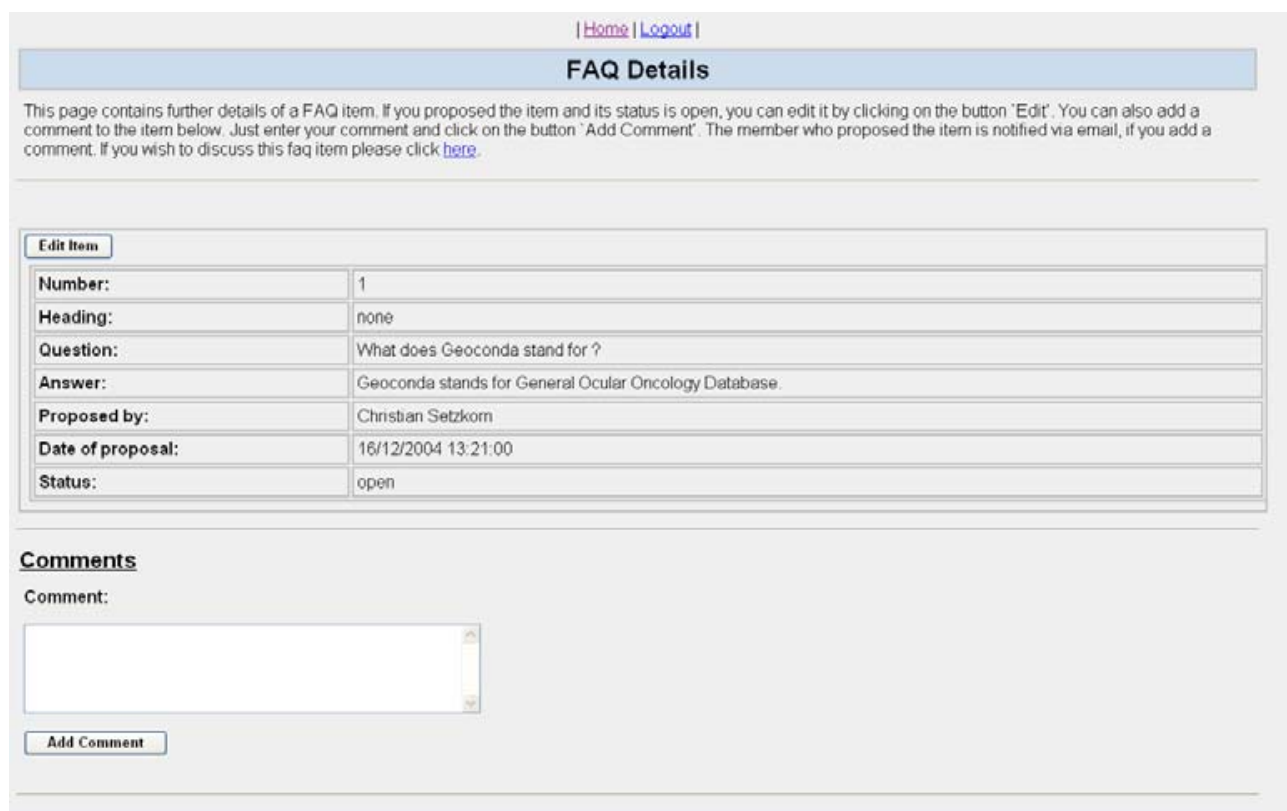

Fig. 8. Details of a FAQ item.

Figure 9 depicts the form, which allows the member who proposed the item to edit it. Changes are stored by pressing the button 'Update'. They are ignored, if the button 'Cancel' is pressed. The field 'Number' allows members to change the order of FAQ items within a category (items are ordered according to this number).

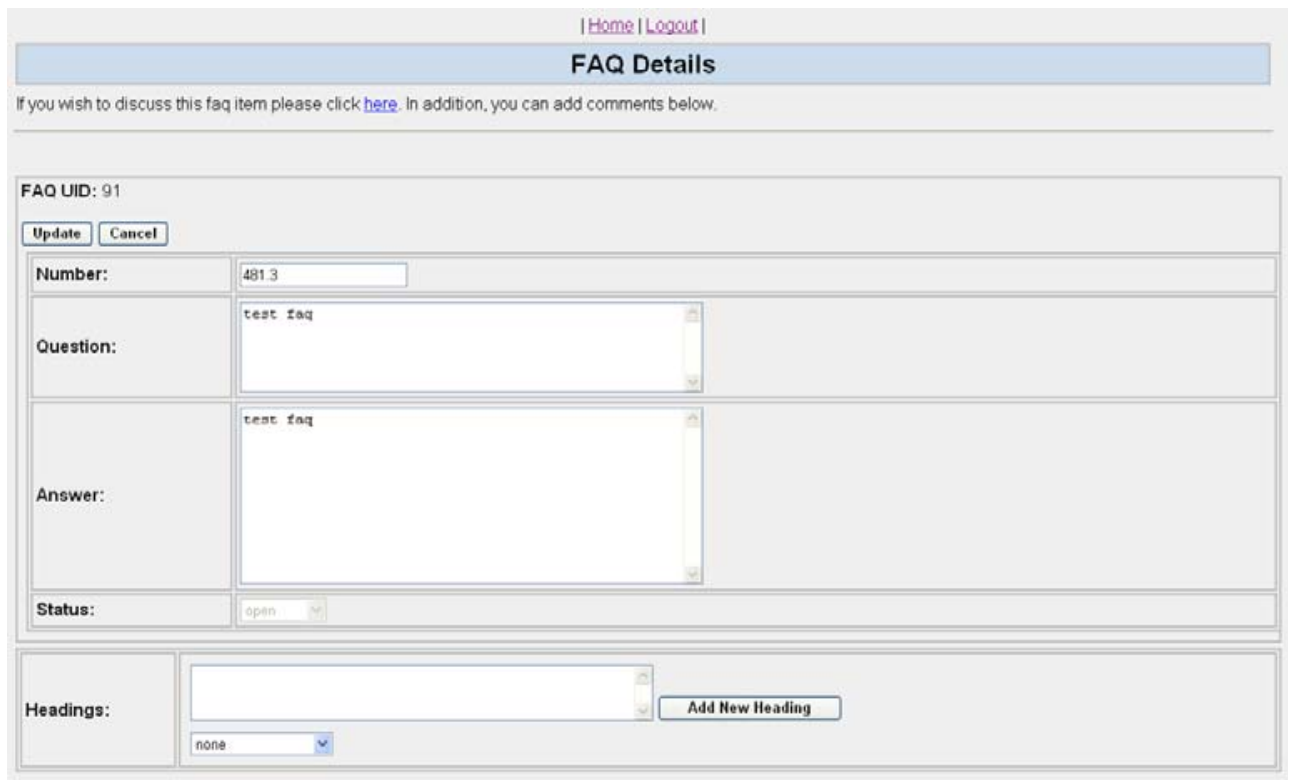

Fig. 9. An FAQ item in the edit mode. 
Positions As in other organisations, the smooth functioning of the Geoconda community requires the existence of official positions that can be occupied by members of the Geoconda community. However, because the Geoconda system is a distributed rather than centralised organisation, the positions have to be created dynamically by the Geoconda community. Hence, similar to other items, members can propose 'position' items. These items are put forward in the same manner as FAQ items. They can have the status: 'open', 'accepted', and 'rejected' and are subject to a review process (see section 2). The fields of a position item are summarised in table 3 .

\begin{tabular}{|l|l|}
\hline Field & Description \\
\hline Position name & Name of the position. \\
\hline Description & $\begin{array}{l}\text { Further details about the position that could, for example, describe the duties of } \\
\text { the member who occupies the position. }\end{array}$ \\
\hline Max number & $\begin{array}{l}\text { Maximum number of members who could be assigned to this position. If the } \\
\text { field is left empty, an unlimited number of members could be assigned to the } \\
\text { position. }\end{array}$ \\
\hline
\end{tabular}

Table 3. Details of the position item.

The member who proposed a position can edit the item, as long as its status is 'open'. Other members can also add comments to an item. This allows a somewhat democratic creation of positions within the Geoconda environment/organisation (see also section 2). Positions can be assigned to members by members with special rights as shown in Figure 10.

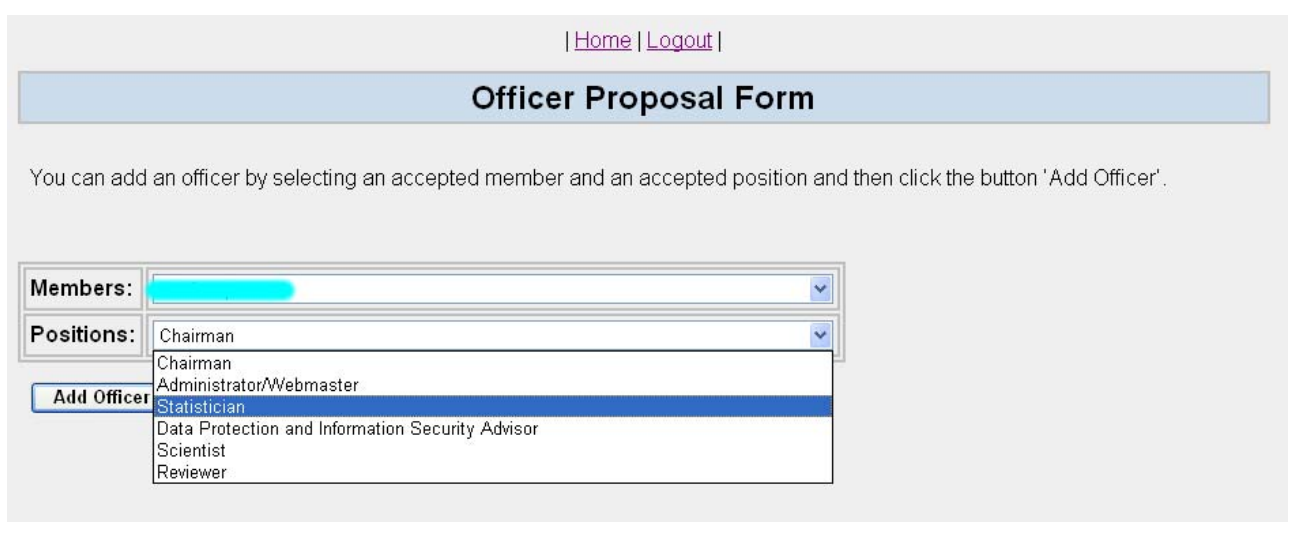

Fig. 10. Assigning a position to a member. The names of Geoconda members who are not authors of this chapter are hidden for privacy reasons.

A member is chosen from the top drop down list and a position from the bottom drop down list. The assignment is finalised by pressing the button 'Add Officer' (members who occupy a position are referred to as officers). 
Variables As mentioned earlier, one of the main objectives of Geoconda is to allow the collection of data from several international institutions via the Internet. To facilitate this, the data collection process has to be standardised. This is necessary, for example, because different institutions might measure particular features using different scales. The standardisation is achieved by variable items, which are proposed by members similar to other items. A member has to choose between six alternative variable types, which are summarised in table 4 .

\begin{tabular}{|l|l|}
\hline Variable Type & Description \\
\hline nominal & $\begin{array}{l}\text { This variable type can be used to model variables with a finite number of two or more } \\
\text { unordered values. Hair colour is an example of a nominal variable. It can have the } \\
\text { values: blonde, brown, brunette and red. }\end{array}$ \\
\hline ordinal & $\begin{array}{l}\text { This variable type can be used to model variables with a finite number of two or more } \\
\text { ordered values. The Likert scale is an example of an ordinal variable. It has the val- } \\
\text { ues: strongly disagree, disagree, neutral, agree and strongly agree. Please note that no } \\
\text { distance is defined between the values of an ordinal variable. }\end{array}$ \\
\hline real & $\begin{array}{l}\text { This variable type can be used to model variables with an (infinite) number of ordered } \\
\text { values such as age, weight and blood pressure. }\end{array}$ \\
\hline datring & $\begin{array}{l}\text { This variable type can be used to model variables, which correspond to strings such as } \\
\text { general comments and postcodes. }\end{array}$ \\
\hline file & $\begin{array}{l}\text { This variable type can be used to model variables, which correspond to dates such as } \\
\text { the birth date of a patient. }\end{array}$ \\
\hline
\end{tabular}

Table 4. Possible variable types.

Apart from specifying a variable type, the member must also provide the information summarised in table 5. It has to be noted that some of the fields are only available for particular variable types. For example, it would not make sense to define a minimum value or measurement unit for a nominal variable.

\begin{tabular}{|l|l|}
\hline Field & Description \\
\hline Name & Unique identifier of the variable that can contain at most eight characters. \\
\hline Label & Long name of the variable that can contain up to 255 characters. \\
\hline Variable Type & Variable type (see table 4). It has to be chosen from a dropdown list. \\
\hline $\begin{array}{l}\text { Description and } \\
\text { Measurement } \\
\text { Protocol }\end{array}$ & $\begin{array}{l}\text { Description of how the variable is obtained/measured. This field might also contain } \\
\text { further information about the variable. }\end{array}$ \\
\hline Optional & $\begin{array}{l}\text { Indicator of whether or not the variable is mandatory. A dropdown list provides a choice } \\
\text { between 'yes' and 'no'. }\end{array}$ \\
\hline Unit & $\begin{array}{l}\text { This information is only required for the variable type 'real'. It indicates the measure- } \\
\text { ment unit of the variable. }\end{array}$ \\
\hline $\begin{array}{l}\text { Minimum num- } \\
\text { ber of decimal } \\
\text { points }\end{array}$ & $\begin{array}{l}\text { of the measurement (minimum number of decimal points). } \\
\text { of information is only required for the variable type 'real'. It dermines the precision }\end{array}$ \\
\hline $\begin{array}{l}\text { Minimum } \\
\text { value }\end{array}$ & $\begin{array}{l}\text { This information is only required for the variable type 'real'. It determines the smallest } \\
\text { possible value. }\end{array}$ \\
\hline $\begin{array}{l}\text { Maximum } \\
\text { value }\end{array}$ & $\begin{array}{l}\text { This information is only required for the variable type 'real'. It determined the largest } \\
\text { possible value. }\end{array}$ \\
\hline $\begin{array}{l}\text { Category Val- } \\
\text { ues/Category } \\
\text { Labels }\end{array}$ & $\begin{array}{l}\text { This information is only required for the variable types 'nominal' and 'ordinal'. It can be } \\
\text { used to model concepts such as Gender. Here the category value '1' might, for example, } \\
\text { correspond to the category label 'male' (see also table 6). It has to be noted that at least } \\
\text { two category values/category labels have to be provided. }\end{array}$ \\
\hline
\end{tabular}


If the variable type is 'nominal' or 'ordinal' the member has to propose at least two pairs of category values/category labels. A category value is a number, whereas the category label describes the 'meaning' of this number in the form of a string. This allows the member to model concepts, such as gender shown in table 6 .

\begin{tabular}{|l|l|}
\hline Category Value & Category Label \\
\hline 0 & female \\
\hline 1 & male \\
\hline
\end{tabular}

Table 6. Possible implementation of the nominal variable gender.

The proposal of the nominal variable gender is illustrated using figure 11 . The form already contains the category values/labels described in table 6 . They were added by completing the fields 'Category Value'/'Category Label' and then clicking on the button 'Add Category'. Categories can be removed by clicking on the hyperlink 'Delete' beside them. The fields 'Category Value'/'Category Label' are filled with the details of the category being deleted. This allows the member to edit the category and possibly add it again. It has to be noted that category values/labels are only accepted if they are unique.

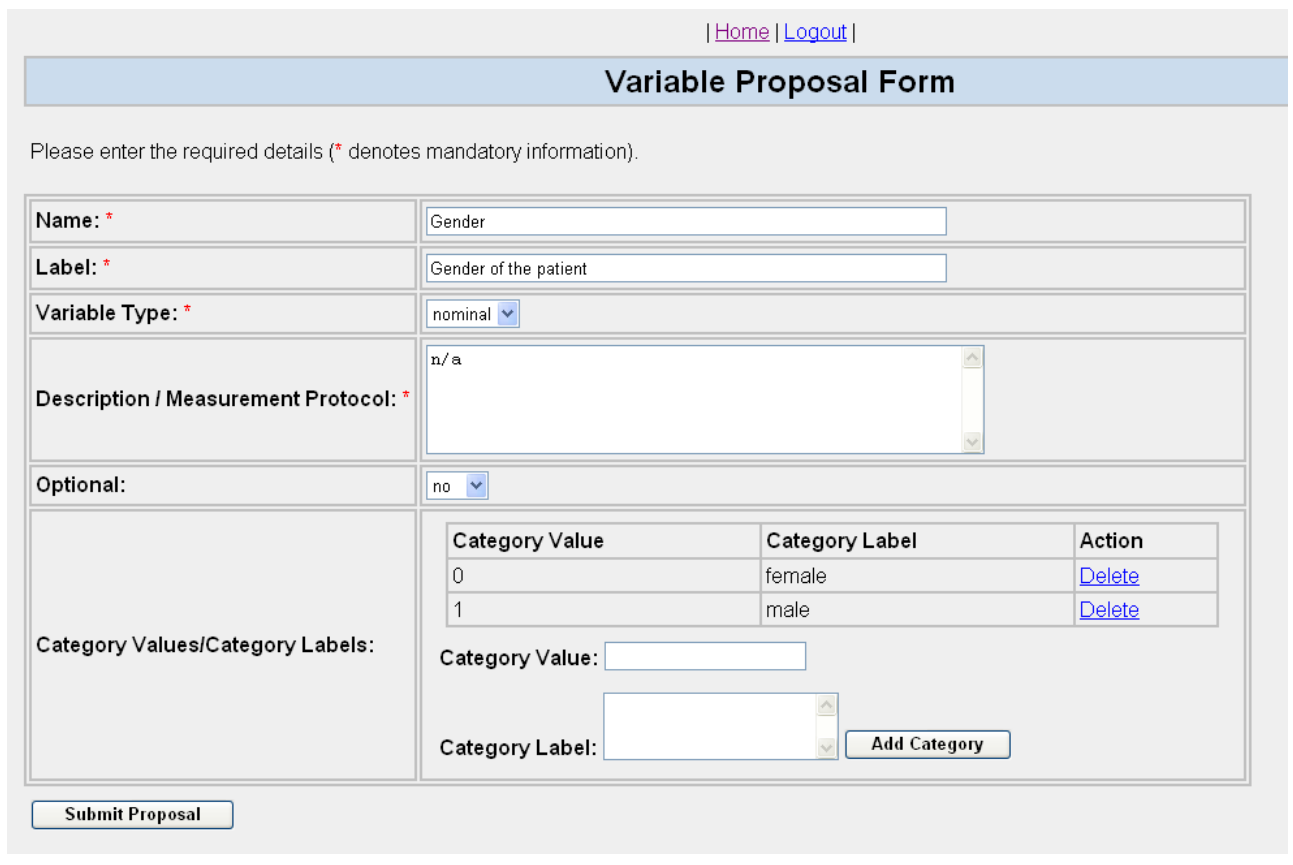

Fig. 11. Proposal form with the details of the gender variable.

The proposal of a variable takes place in the same manner as for other items. The item is submitted by clicking on the button 'Submit Proposal'. It can have the status: 'open', 'accepted', and 'rejected' and undergoes a review process. Other members can also add comments. Members who proposed a variable item can edit it, as long as its status is 'open'. This allows members to refine the item and to incorporate the comments of other members. Hence, it increases the chance that the review committee will accept the variable and that the variable is actually used in multi-centre studies (see also section 2).

All proposed variable items are listed in the variable section of Geoconda. It is possible to view the variables in chronological or alphabetical order. Furthermore, for practical reasons it is possible to restrict the number of shown variables according to their usage ${ }^{2}$ and their status.

\footnotetext{
${ }^{2}$ Usage refers to the number of times the variable is used in a project.
} 
Glossaries Collaborations between several international centres require the standardisation of terminologies, because not all members work in the same problem domain. Glossary items assist this process. They are proposed in the same manner as the other items and can have the status: 'open', 'accepted', and 'rejected' and are subject to a review process (see section 2). The information summarised in table 7 have to be provided to propose a glossary item.

Field $\quad$ Description

\begin{tabular}{l|l}
\hline Name & Name of the glossary item.
\end{tabular}

Details Further details of the glossary item.

Image $\quad$ This field provides the member with the opportunity to add a picture to the glossary item. The picture is uploaded from the local file system of the member using a browsing facility (see button 'Browse').

Table 7. The glossary item fields.

Members who propose glossary items can edit them as long as their status is 'open'. This allows members to incorporate comments from others, making the acceptance of the glossary item by the committee of reviewers more likely (see also section 2). 
Projects To encourage international collaborations, members can propose project items. It has to be noted, however, that projects require the existence of accepted variables (each project must contain at least one accepted variable). Variables are assigned to a project during the proposal process. Members can also be assigned to a project. They are referred to as participants and can share project specific data with the member who proposed the project (after the project has been accepted). It has to be noted that each participant has the right to delete/edit his/her own data. Data can be shared as described in section 3.2. A member who would like to propose a project has to provide the information summarised in table 8 .

\begin{tabular}{|c|c|}
\hline Field & Description \\
\hline Short Title & Unique short name for the project. \\
\hline Full Title & Title of the project that would appear in the published article. \\
\hline Public & $\begin{array}{l}\text { This field indicates whether or not the project is public. A dropdown list offers a choice } \\
\text { between 'yes' and 'no'. If 'no' is chosen; only the member who proposed the project, } \\
\text { the participants, and the current author can view the project details. If 'yes' is chosen, } \\
\text { everyone can view the project details. }\end{array}$ \\
\hline Aims & Aims of the study, as they would appear in the published article. \\
\hline Background & $\begin{array}{l}\text { Background information that would form the basis of any grant or ethical committee ap- } \\
\text { plications, patient information sheets, and the introduction of any published articles. }\end{array}$ \\
\hline Patients & Inclusion/exclusion criteria for patients considered for enrolment in the study. \\
\hline Material & $\begin{array}{l}\text { Descriptions of any materials, such as pharmaceutical or other agents, which will be used } \\
\text { in the project. }\end{array}$ \\
\hline Methods & $\begin{array}{l}\text { Description of the methods such as the examination and treatment techniques, statistical } \\
\text { methods and follow-up protocols. }\end{array}$ \\
\hline Main Results & Main results of the study. \\
\hline Discussion & $\begin{array}{l}\text { Brief summary of the most important findings; the main strengths and weaknesses of the } \\
\text { study, comparisons with other studies; scope for further work; clinical implications; and } \\
\text { conclusion. }\end{array}$ \\
\hline Comments & $\begin{array}{l}\text { Any comments relevant to the project, such as pending issues relevant for the successful } \\
\text { completion of the project. }\end{array}$ \\
\hline $\begin{array}{l}\text { Ethical Com- } \\
\text { mittee }\end{array}$ & $\begin{array}{l}\text { Statement as to whether or not ethical committee approval is required, together with infor- } \\
\text { mation on where specimen application forms, consent forms, patient information sheets } \\
\text { can be obtained. }\end{array}$ \\
\hline References & This field contains literature references relevant to the study. \\
\hline Co-Workers & $\begin{array}{l}\text { Information about people who are involved in the design of the study, analysis of the } \\
\text { results and/or writing of the manuscript. }\end{array}$ \\
\hline Participants & $\begin{array}{l}\text { The member who proposes a project can assign other members (participants) to the } \\
\text { project. The participants can share the data submitted to the project. Each participant has } \\
\text { the right to delete/edit his/her own data. }\end{array}$ \\
\hline Variables & $\begin{array}{l}\text { The member who proposes a project must assign at least one accepted variable to the } \\
\text { project. Samples for this project will consist of these variables. }\end{array}$ \\
\hline
\end{tabular}

Table 8. Details of a project item.

Similar to other items, project items have the status 'open' after their proposal and other members can add comments to it. Project items also undergo a review process after which their status is either changed to 'accepted' or 'rejected' (see section 2). It has to be noted that the member who proposed a project can add new participants to the project, even if the project is already accepted. This makes the member who proposed the project more flexible to create additional collaborations to share data.

Members who propose project items can also transfer the 'authorship' of the project to other members. Whoever owns the authorship can change the content of the project details as 
long as its status is 'open'. It has to be noted that the member with the authorship can pass it on to other members. However, the member who proposed the project can always recover the authorship by assigning it to himself/herself.

Variables can be assigned to a project as illustrated in figure 12. The left list shows all variables that were not assigned to the project in alphabetical order. A variable can be assigned to the project by pressing the button 'move right'. Variables appear in the right list in the order they have been assigned to the project. The order of the variables can be changed by selecting a variable and pressing the button 'move up' and 'move down'. The proposed order is used to dynamically generate the online forms for the collection of data for this project. To impose a particular order of the variables can be beneficial, for example, in a clinical environment where the data are collected according to a semantic rather than an alphabetical order.

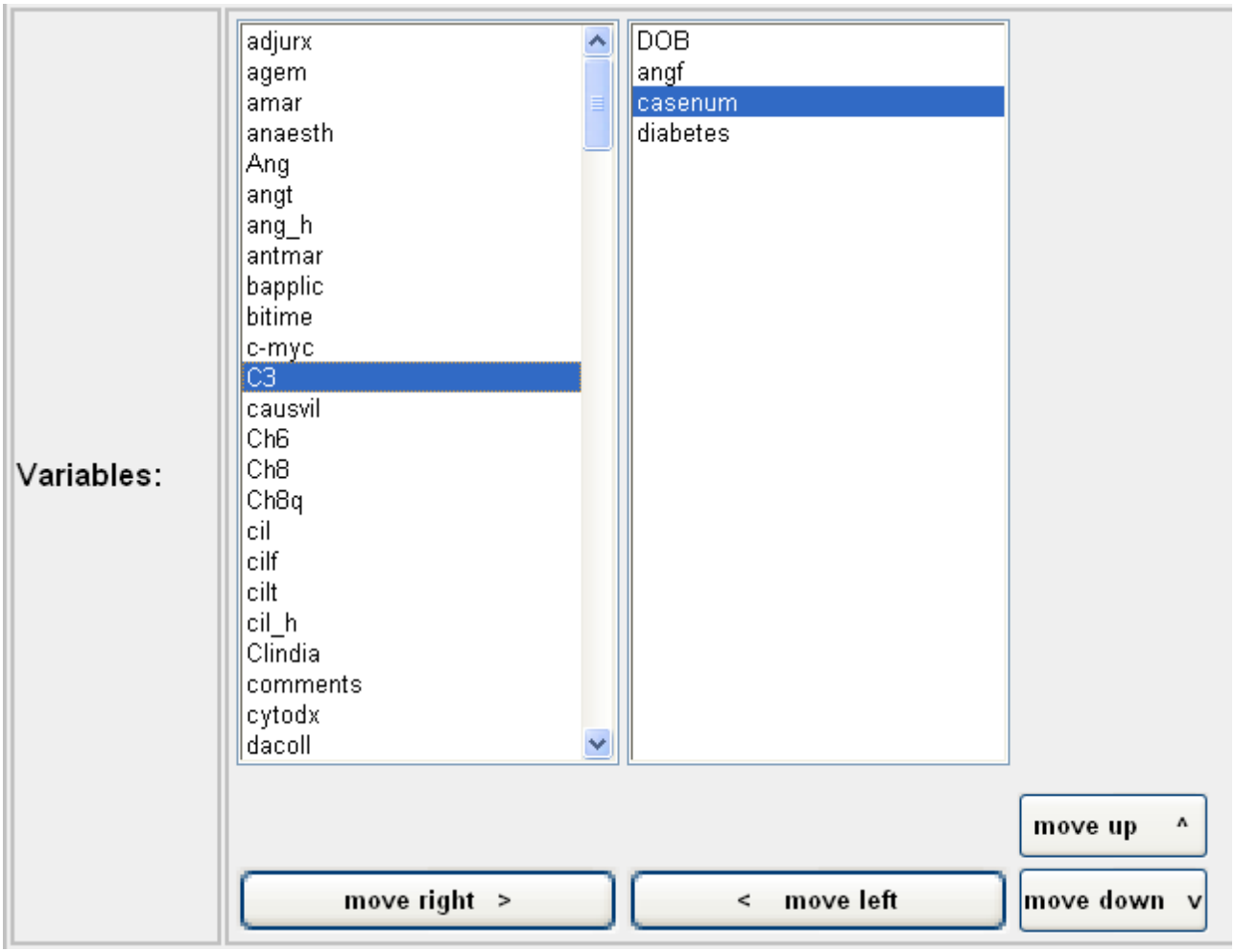

Fig. 12. Assigning of variables to a project.

Accepted members can be assigned to the project as described for the variables. These members are referred to as participants.

Links Link items enable members to make other members aware of other relevant web pages. They are proposed in a similar manner as other items. The member has to provide the information summarised in table 9 .

Similar to all the other items, a link has the status 'open' after its proposal. It also undergoes a review process, which is described in section 2 . Other members can also add comments to link item. 


\begin{tabular}{|l|l|}
\hline Field & Description \\
\hline Name & Short name for the link that can contain at most 45 characters. \\
\hline Link & $\begin{array}{l}\text { Link to the actual website, which is also often referred to as URI (Uniform } \\
\text { Resource Identifiers) or URL (Uniform Resource Locator). }\end{array}$ \\
\hline Description & Short description of the referred web page. \\
\hline
\end{tabular}

Table 9. Details of a link item.

\subsection{Data}

To share and accumulate large amounts of data is the main objectives of the Geoconda system. Data consist of samples, which consist of values of variables that were assigned to a particular project. To ensure the smooth functioning of multi-centre data submission, particular rules for the submission of data were agreed on by the developers of the Geoconda system. For example, data can only be submitted to accepted projects. Furthermore, only the member who proposed a project and the participants of the project can submit/retrieve data to/from a project.

Data can be submitted from files (located on the computer of the particular member) or manually via dynamically created forms (the forms contain entries for the variables that were assigned to the project). There are additional rules for the submission of data from files. Before these rules are detailed, the concept of the Local Unique Identifier (LUID) has to be introduced. LUIDs are strings that are necessary to allow members to identify their samples after they were submitted to a particular project. As the name suggests, each LUID string has to be unique for all the samples a particular member submits to a project. The database itself assigns a Global Unique Identifier (GUID) to each sample. Both the LUID and the GUID allow the merging of data from different research centres/members without losing the information about the origin of a sample. Please note, however, that other members do not know the LUIDs of samples from other members to maintain confidentiality. The following list summarises the rules for the submission of data from files.

- Datasets can only be submitted from files if the associated project does not contain variables of type 'file'. If the project contains variables of type 'file', samples can only be submitted manually.

- Dataset columns can be delimitated by the characters '- ', ', , , or ';' . The particular delimiter is chosen from a dropdown list.

- The first row of a dataset file can only contain variable names associated with the project. The order of the variable names is not relevant and the number of variable names must not be complete. Missing variable values are left blank and can be edited later.

- The first row of the dataset file must contain a LUID column. If it does not contain a LUID column, the dataset file is rejected.

- Each LUID variable value in the LUID column must be unique. Otherwise the dataset is rejected.

- If a member resubmits samples from a file (samples with the same LUID value in the database) the original samples in the database are automatically overwritten without warning.

- Files can only contain variable names that are associated with the project. The dataset file is rejected if it contains unknown variable names.

Members can submit data to a project by clicking on the button 'Data' shown in figure 2 . Figure 13 shows the first page of the data section. The dropdown box lists all the projects the member proposed or participates in (the Geoconda system knows the identity of the member after his/her login). Figure 13 also contains three buttons. The first two buttons allow you to submit data manually or from a file respectively. The third button allows the member to retrieve or edit data. It has to be noted that the button 'Submit Data From File' only appears for projects that do not contain variables of type 'file'. 
Project: Biopattern SP17 Training Set v

Submit Data Manually

Submit Data From File

Fig. 13. First page of the data section.

The retrieved data for the 'test project' are shown in figure 14 and figure 15. They were obtained by clicking on the button 'Retrieve / Edit Data'. The member can either view his/her own data (see figure 14) or all project data which were submitted by all the participants of the project (see figure 15).

| Home $\mid$ Logout $\mid$

Data Retrieval For Project: test_project

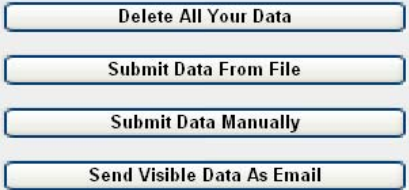

O All Project Data ○ Your Project Data

\begin{tabular}{|l|l|l|l|l|}
\hline & Database ID (GUID) & Your ID (LUID) & Gender \\
\hline Edit & Delete & 9514 & $\times$ (1) & 1 \\
\hline Edit & Delete & 9515 & 2 & 0 \\
\hline
\end{tabular}

Fig. 14. Retrieved data for the 'test project'. This view only shows samples that were submitted by the member who is logged in.

The member who proposed the project or its participants can also edit and delete his/her own samples and submit additional samples either manually or from a dataset file. The member can retrieve the visible data by pressing the button 'Send Visible Data As Email'. Internally a comma delimitated file containing the depicted data is assembled and send via email as attachment to the participant. 
| Home $\mid$ Logout $\mid$

Data Retrieval For Project: test_project

\begin{tabular}{|c|c|c|c|}
\hline \multicolumn{4}{|c|}{ Delete All Your Data } \\
\hline \multicolumn{4}{|c|}{ Submit Data From File } \\
\hline \multicolumn{4}{|c|}{ Submit Data Manually } \\
\hline \multicolumn{4}{|c|}{ Send Visible Data As Email } \\
\hline \multicolumn{4}{|c|}{ ( All Project Data O Your Project Data } \\
\hline Database ID (GUID) & Submission Date & Last Update Date & Gender \\
\hline 9514 & $17 / 05 / 200510: 25: 03$ & $17 / 05 / 200510: 25: 03$ & 1 \\
\hline 9515 & $17 / 05 / 2005$ 10:25:10 & $17 / 05 / 2005$ 10:25:10 & 0 \\
\hline 9516 & $17 / 05 / 200510: 27: 20$ & $17 / 05 / 200510: 27: 20$ & 0 \\
\hline 9517 & 17/05/2005 10:27:27 & $17 / 05 / 200510: 27: 27$ & 1 \\
\hline 9518 & $17 / 05 / 2005$ 10:27:46 & $17 / 05 / 200510: 27: 46$ & 1 \\
\hline
\end{tabular}

Fig. 15. Data for the 'test project'. The data consist of all samples that were submitted by all members who participate in the chosen project.

The manual submission of data is illustrates in Figure 16. All variables associated with the project are shown in the order defined during the project proposal, apart from the LUID variable which is always at the top of the list. The chosen project contains variables of type file, which means that the members can upload files from their local file system. Files can be of any kind but their size is, for practical reasons, restricted to one mega byte. It is important to note that the Geoconda system stores the file under a unique name and the original name is stored in the database.

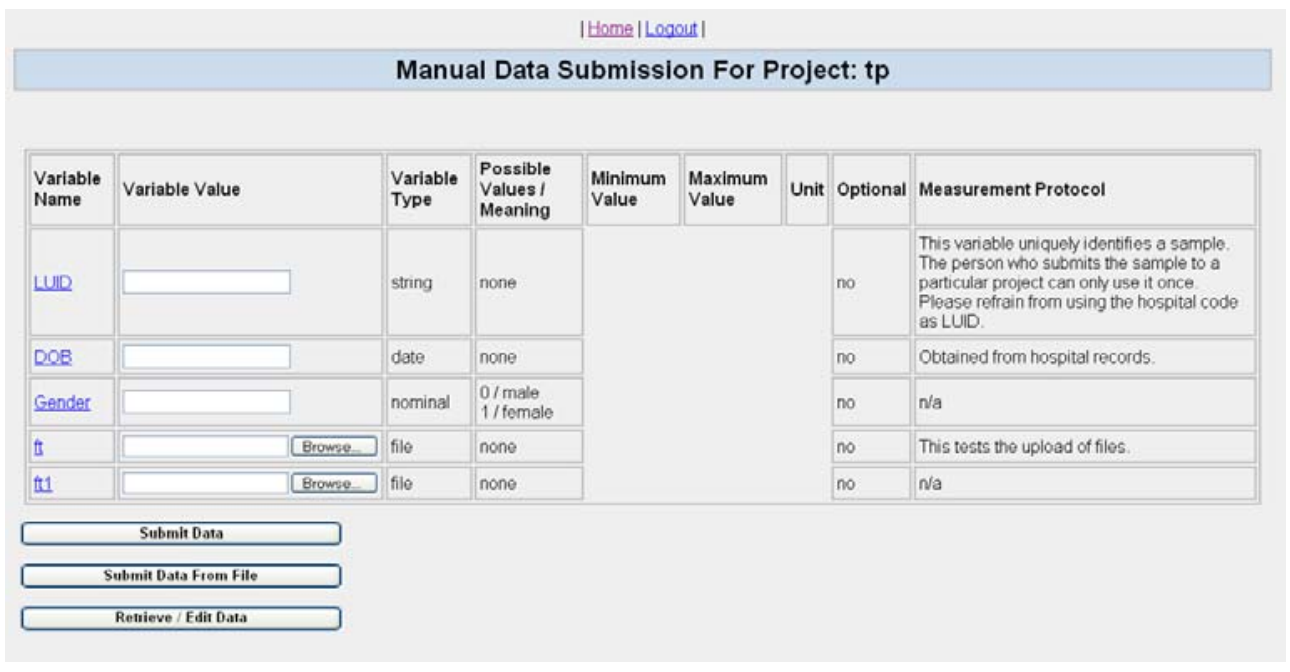

Fig. 16. Manual submission of data to a chosen project that contains variables of type file. 
Figure 17 illustrates the retrieval of data for a project that contains variables of type 'file'. Participants of a project can retrieve data by clicking on the button 'Send Visible Data As Email'. However, these data do not contain the files that were submitted to the project. To obtain the actual files, participants have to click on each file name individually. The file name is shown as a hyperlink. An email is send to the participant containing the file as attachment.

| $\underline{\text { Home }}|\underline{\text { Logout }}|$

\section{Data Retrieval For Project: tp}

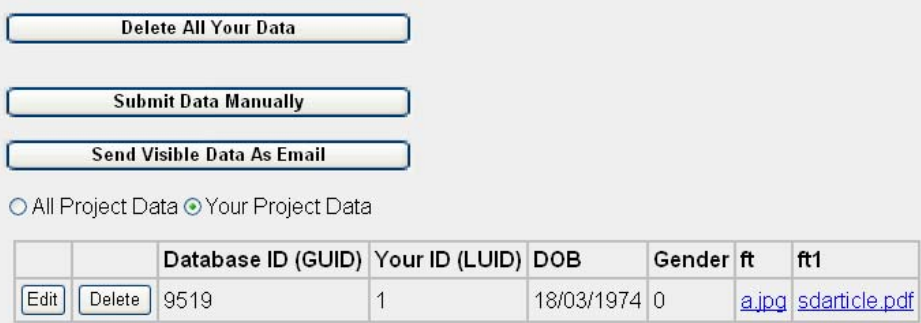

Fig. 17. Data retrieval for a project that contains variables of type file.

\subsection{Online Papers}

Members can propose online papers, which can be edited by several people via the Internet. To propose a paper the information summarised in table 10 have to be provided.

\begin{tabular}{|l|l|}
\hline Field & Description \\
\hline Title & The title of the online paper. \\
\hline Public & $\begin{array}{l}\text { This field indicates whether the paper is public (value 'yes') or not (value 'no'). } \\
\text { If the paper is not public, only the member who proposed the paper and the co- } \\
\text { authors can access its content. Otherwise, every member can view the content } \\
\text { of the paper. }\end{array}$ \\
\hline Abstract & The abstract of the paper. \\
\hline Co-Authors & $\begin{array}{l}\text { A list of co-authors who can edit the paper together with the member who pro- } \\
\text { posed the paper. }\end{array}$ \\
\hline
\end{tabular}

Table 10. The online paper item fields.

Figure 18 shows a fraction of the online paper proposal form. Co-authors, who can edit the paper later together with the member who proposed the paper, can be assigned to the paper in by selecting a member from the list on the left-hand side and clicking the button 'move right'. The content of the paper can be edited similar to a standard text editor. This enables one to, for example, format the text and create tables. In fact, the editor allows one to insert pictures and even animations. 


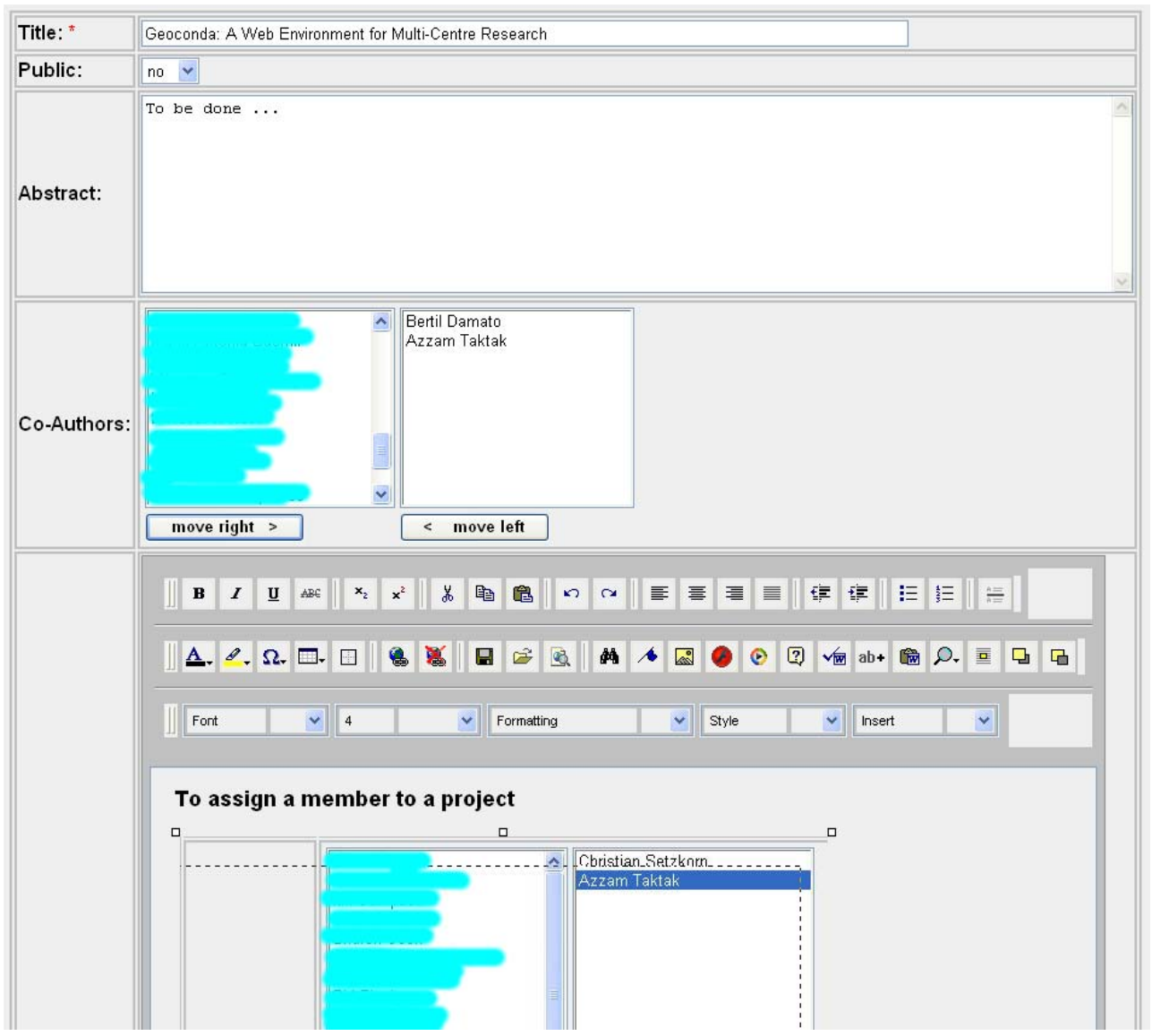

Fig. 18. Proposal of an online paper. The names of Geoconda members who are not authors of this chapter are hidden for privacy reasons.

It has to be noted that the online paper facility can cope with multi-user updates. This is important, as many people can try to change the same paper at the same time.

\subsection{Discussion Forums}

The Geoconda system also contains several discussion forums, which were implemented using an existing tool called phpBB ${ }^{3}$. The discussion forums allow members to exchange information on particular subjects in a very interactive manner. There are currently five forums as shown in figure 19.

Some of these forums are moderated and require members to register. This means that not everyone can submit/retrieve entries to/from a discussion forum. This ensures privacy, because confidential forums could be accessed from the Internet.

\subsection{Mailing List}

The Geoconda system also hosts a mailing list. The mailing list simplifies the communication between the members. In addition, it will help to broadcast news. It has to be noted that the mailing list is moderated. This means that not everyone can post messages, which decreases the likelihood of Spam emails.

\footnotetext{
${ }^{3}$ It can be downloaded free of charge from the website http://www.phpbb.com/.
} 


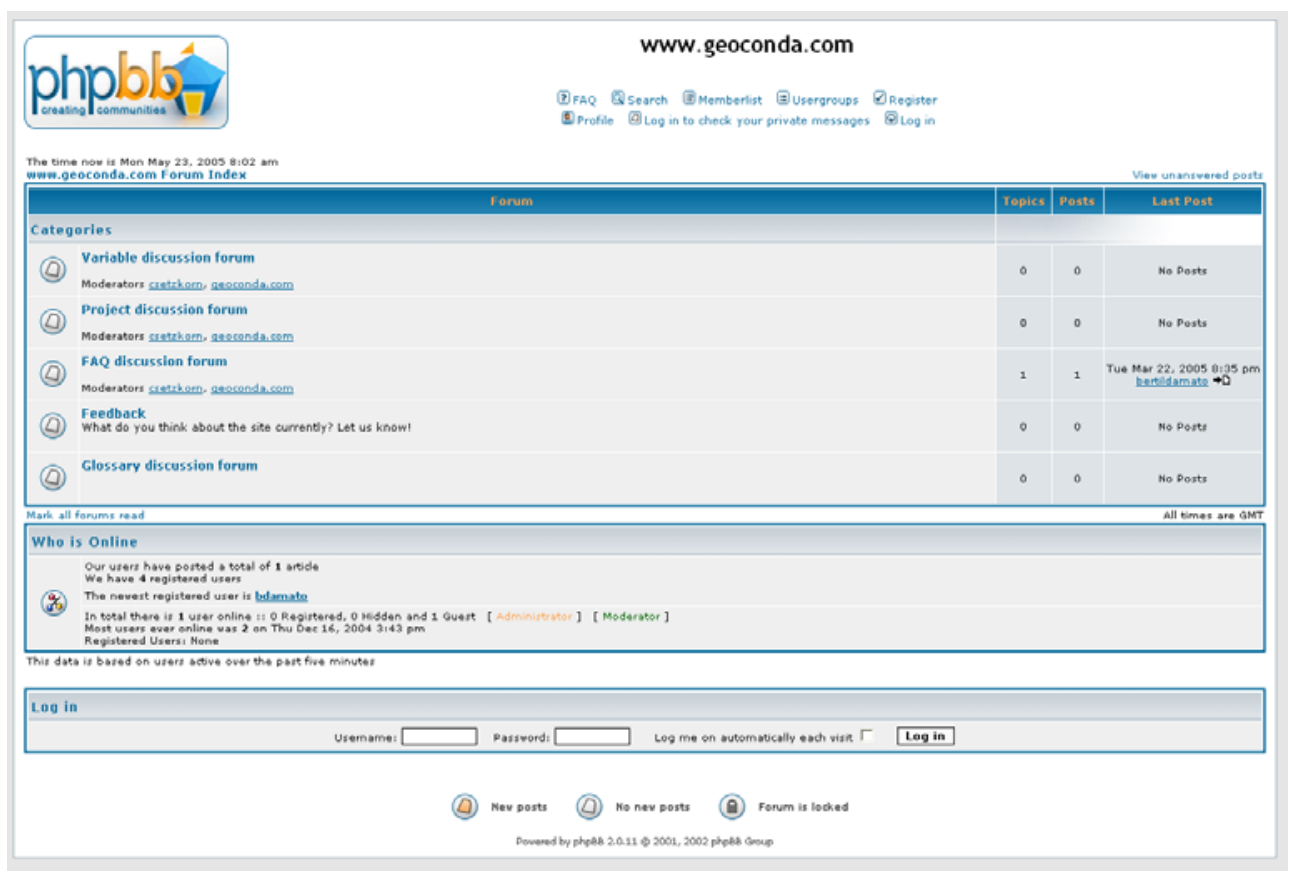

Fig. 19. The current discussion forums.

\section{Discussion}

Several requirements have to be fulfilled for successful multi-centre research. For example, all members must be able to communicate with each other in a free and convenient manner. All data must be collected and stored in a standardized manner. The data must be stored securely, respecting the confidentiality of both patients and project participants. There must be full compliance with all relevant regulations pertaining to matters such as data protection, human rights, and publication rights. The website we have created facilitates this.

An environment is provided for clinicians and scientists from different disciplines to communicate with each other, by means of e-mail (lists), comments, and discussion forums. Special measures were taken to enable each individual to obtain information on members, positions, regulations, variables, projects etc. quickly and conveniently.

The website is designed to be very dynamic to be responsive to the needs of the members. To enable continuous and efficient evolution, a variety of forms allow to proposal of new items, their discussion, amendment, and review by experts. Such transparency provides all members with a sense of ownership and collective responsibility.

Patient confidentiality is guaranteed by disallowing storage of hospital number, surnames, addresses, telephone number or any other personal details that would allow an individual to be identified. Practitioner/centre confidentiality is respected allowing project participants to identify only their own patients.

It is recognized that teams of researchers will wish to protect their intellectual property. Each project can therefore be classified as non-public, so that all details are only available to participants of that project. The chairperson and other officials do not have access to details regarding private studies.

Responsibility for compliance with national laws, local hospital regulations, and ethical committee requirements lies entirely with the member who proposed a project. The committee is unable to police all projects, particularly those that do not have public access. Consideration is being given to appointing a compliance officer, who would have access to all projects, 
public or private, to ensure that standards are maintained. It is also the responsibility of each project leader to organize validation and verification of data, selection of appropriate statistical methods, and prevention of fraud and plagiarism.

Using ASP.NET form authentication ensures the security of the Geoconda system. Each member has to use a password to log into the system. The passwords are stored in encrypted form in the database to ensure further security. The Internet service provider generates backups every day.

\section{Summary and Conclusions}

This chapter has introduced the Geoconda system, which uses a website and a relational database to facilitate international research collaborations. Table 11 provides some statistics of the website, which is online since December of 2004.

\begin{tabular}{|l|l|l|l|}
\hline Item & Number of items & Number of accepted items & Further details \\
\hline Officers & 10 & n/a & n/a \\
\hline Positions & 7 & 0 & n/a \\
\hline FAQs & 52 & 0 & n/a \\
\hline Members & 46 & 46 & Members are from 13 different countries. \\
\hline Variables & 252 & 185 & n/a \\
\hline Glossary & 70 & 6 & n/a \\
\hline Projects & 19 & 10 & n/a \\
\hline Links & 10 & 0 & n/a \\
\hline Samples & 5863 & n/a & n/a \\
\hline Online Papers & 1 & 0 & n/a \\
\hline
\end{tabular}

Table 11. Current statistics of Geoconda.

The Geoconda system is currently used for several international collaborations between four different countries: Greece, Italy, Netherlands and the United Kingdom. These projects evaluate different approaches for survival analysis and classification in a double-blind manner.

Survival analysis is used to estimate the probability of survival following treatment of uveal melanoma. Estimating the probability of survival in cancer has a number of benefits. It allows clinicians to review their practice and advice their patients on the best course of treatment. It also allows patients to plan their lives and provide future care for their dependents. There are numerous algorithms for estimating the probability of survival including the KaplanMeier non-parametric model, the proportional hazard model by Cox and Artificial Neural Networks $[2,4,3]$. Although some researchers have conducted direct comparison between different models, as far as we are aware, none have conducted multi-centre studies on a common dataset. 


\section{Future Work}

To provide the user with more flexibility and expressiveness in adding content to the Geoconda system, standard text boxes are currently replaced with so-called WYSIWYG entry fields (WYSIWYG stands for: 'what you see is what you get'). Standard text boxes only allow users to submit fields that contain text. This is not very useful, if one would like to submit more complex information (e.g. tables, pictures, animations). A WYSIWYG entry field is shown in Figure 20. It contains several buttons, which allow the user to add, for example, tables and pictures. It also enables one to format the text similar to other well-know editors.

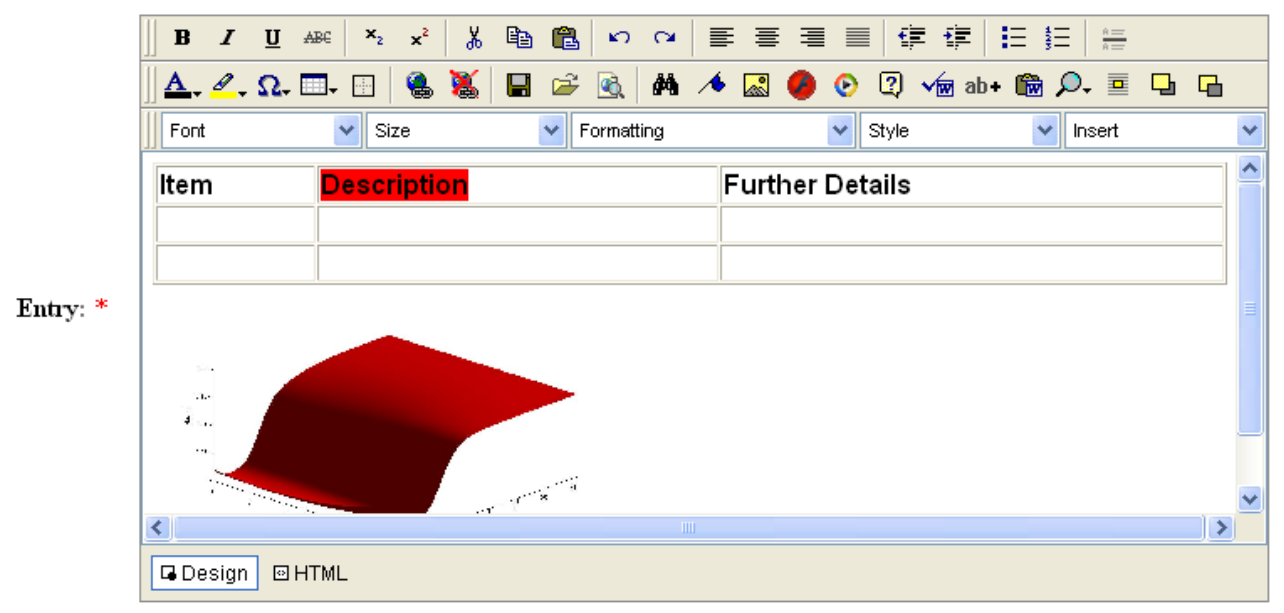

Submit

Fig. 20. A WYSIWYG (what you see is what you get) entry field.

An WYSIWYG entry field is currently only used for the item 'Online Papers' described in section 3.1. However, it could also be very useful for items such as 'glossaries', which could contain pictures and tables or variable definitions.

\section{References}

1. A. Homer, D. Sussman, R. Howard, B. Francis, K. Watson, and R. Anderson. Professional Asp.Net 1.1. Hungry Minds Inc,U.S., 2004.

2. D. Kleinbaum. Survival analysis: A self-learning text. Springer, 1996.

3. C. Setzkorn, A. Taktak, and B. Damato. Survival analysis using a multi-objective evolutionary algorithm. In Proceedings of the Second International Conference on Computational Intelligence in Medicine and Healthcare - CIMED 2005, pages 224-230, 2005.

4. A. Taktak, A. Fisher, and B. Damato. Modelling survival after treatment of intraocular melanoma using artificial neural networks and bayes theorem. Physics in Medicine and Biology, 49(1):87-98, 2003. 